\title{
Antioxidant activity and short-chain fatty acid production of lactic acid bacteria isolated from Korean individuals and fermented foods
}

\author{
Chang-Ho Kang ${ }^{1}\left[\right.$ D Jin-Seong Kim ${ }^{1} \cdot$ Hye Min Park ${ }^{1} \cdot$ Seonyoung Kim ${ }^{1} \cdot$ Nam-Soo Paek $^{1}$
}

Received: 14 December 2020 / Accepted: 29 March 2021 / Published online: 15 April 2021

(c) The Author(s) 2021

\begin{abstract}
Compounds of the cell walls of heat-killed lactic acid bacteria show immunomodulatory properties which boost immunological systems, and are used ad postbiotics (paraprobiotics). In this study, we used 17 different heat-killed isolates as postbiotics and evaluated their anti-inflammatory potential on the expression of proinflammatory mediators and cellular signaling pathways of murine macrophage, RAW 264.7 cells. Bifidobacterium bifidum MG731 showed the high 2,2-diphenyl-1-picrylhydrazyl (DPPH) free radical scavenging activity (90.6\%), followed by Bifidobacterium lactis MG741 (59.6\%). The Bi. lactis MG741 showed the high ABTS free radical scavenging activity (99.5\%), followed by Lactobacillus plantarum MG989 (98.9\%), Lactobacillus salivarius MG242 (97.1\%), and Bi. bifidum MG731 (96.1\%). In addition, Bi. bifidum MG731 showed the lowest nitric oxide production $(4.28 \mu \mathrm{M})$, followed by B. lactis MG741 $(10.80 \mu \mathrm{M})$, L. salivarius MG242 $(14.60 \mu \mathrm{M})$, and L. plantarum MG989 $(19.60 \mu \mathrm{M})$. The selected strains showed a decreased nitric oxide production via downregulation of inducible nitric oxide synthase and cyclooxygenase 2, which were upregulated via LPS-stimulated RAW 264.7 macrophages. Short-chain fatty acids (SCFA) including acetic, propionic, and butyric acid were produced by four strains. The

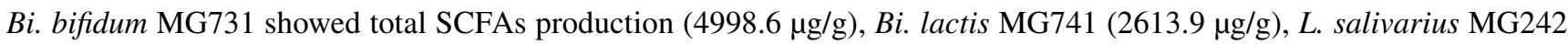
$(1456.1 \mu \mathrm{g} / \mathrm{g})$, and $L$. plantarum MG989 $(630.2 \mu \mathrm{g} / \mathrm{g})$. These results indicated that the various selected strains may possess an anti-inflammatory potential and provide a molecular basis for the development of functional probiotics.
\end{abstract}

Keywords Probiotics $\cdot$ Antioxidant $\cdot$ Anti-inflammation $\cdot$ Short-chain fatty acid

\section{Introduction}

Probiotics are defined as "living microorganisms that have health benefits beyond inherent basic nutrition" when consumed in certain quantities (Klein et al. 1998; Rendondo et al. 2019). According to the current definition, a probiotic must contain viable cells; therefore, it is not applicable to dead bacterial cells or cell components. Postbiotics are soluble factors (products or metabolic by-products) either secreted by live bacteria (such as probiotic or non-probiotic), or released after bacterial lysis, that may be beneficial to the host (Aguilar-Toalá et al. 2018). The mechanisms implicated in most bioactivities of postbiotics are not fully understood; scientific evidence supports that postbiotics possess diverse functional/bioactive properties such as antimicrobial,

Chang-Ho Kang

changho-kang@naver.com

1 MEDIOGEN Co. Ltd., Biovalley 1-ro, Jecheon-si, Chungcheongbuk-do, Incheon 27136, Korea antioxidant, and immunomodulatory activities via direct (interaction with the intestinal microbiota or immune cells) or indirect (outside the gastrointestinal tract, in the immune system and other organs) pathways (Aguilar-Toalá et al. 2018; de Almada et al. 2016; Sharma and Shukla 2016).

Inflammation is a complex response of the vascular tissues to harmful stimuli, such as pathogens, damaged cells, or irritants. It is mediated by a variety of signaling molecules produced by macrophages, monocytes, and mast cells. The stimulus is persistent in chronically inflamed tissues; therefore, recruitment of the monocytes is maintained and existing macrophages are tethered in place. Macrophages play an important role in the innate immunity as they are one of the first cells to respond to microbial infection. They can kill pathogens directly via phagocytosis and indirectly via the secretion of proinflammatory cytokines such as tumor necrosis factor alpha (TNF- $\alpha$ ), interleukin 1 beta (IL-1 $\beta$ ), and interleukin 6 (IL-6) (Stuehr et al. 1991; Kazemi et al. 2019), as well as excess amounts of mediators such as nitric 
oxide (NO), and prostanoids in response to lipopolysaccharide (LPS) stimulation.

Short-chain fatty acids (SCFAs) such as butyrate, propionate, and acetate are produced via fermentation of indigestible carbohydrates by intestinal anaerobic commensal bacteria such as Clostridia species; they impact both nonimmune as well as immune intestinal cells (Koh et al. 2016). SCFAs play an important role in innate immunity as they are histone deacetylase (HDAC) inhibitors with antiinflammatory effects (Willemsen et al. 2003). Additionally, SCFAs play a role in the adaptive intestinal immunity (Willemsen et al. 2003). It was shown that the administration of butyrate, acetate, and propionate to germ-free mice increases the expression of anti-inflammatory interleukin 10 (IL-10) producing Foxp3-expressing regulatory T cells (Tregs) via HDAC inhibition (Smith et al. 2013). Moreover, butyrate increases interleukin 18 (IL-18) expression in epithelial cells, increases the IL-10 expression in dendritic cells and macrophages, and enables them to induce the differentiation of Tregs, thereby conferring protection against colitis (Singh et al. 2014). Therefore, SCFAs affect both nonimmune as well as immune intestinal cells and modulate intestinal homeostasis.

Although these studies have reported the functional activities of various lactic acid bacterial strains, lactic acid bacteria strains against LPS-induced inflammation have not yet been reported. Therefore, we aimed to evaluate the antiinflammatory potential of 17 lactic acid bacterial strains. The effects of 17 heat-killed lactic acid bacteria on the expression of proinflammatory mediators and cellular signaling pathways were investigated in LPS-induced murine macrophage, RAW 264.7 cells.

\section{Materials and methods}

\section{Sample preparation}

In this study, 17 strains were isolated from Korean individuals and fermented food products (Kim et al. 2020). The selected strains were identified by the 16S rRNA gene sequencing method (SolGent Co., Ltd. Korea). The strains were cultured in de Man, Rogosa, and Sharpe (MRS) broth (BD Biosciences, Frankin Lakes, NJ, USA) at $37{ }^{\circ} \mathrm{C}$ and the strains were stored at deep freezer $\left(-80^{\circ} \mathrm{C}\right)$ in $20 \%(\mathrm{v} / \mathrm{v})$ glycerol. To evaluate the anti-inflammatory potential of these strains, selected strains that were cultivated overnight were heat-killed at $90{ }^{\circ} \mathrm{C}$ for $30 \mathrm{~min}$. Following centrifugation $(12,000 \times \mathrm{g}, 5 \mathrm{~min})$, the cell pellets were rinsed thrice with phosphate-buffered saline (PBS) and suspended in Dulbecco's modified Eagle media (DMEM) (BD Biosciences) to obtain concentrations of $5 \times 10^{8}$ cells $/ \mathrm{mL}$ by adjusting the solution based on absorbance at $600 \mathrm{~nm}\left(\mathrm{OD}_{600}\right)$. The mixture samples comprised mixed cultures of the 17 strains in a same ratio, respectively, and freeze-dried.

\section{In vitro antioxidation properties of the selected strains}

The 2,2-diphenyl-1-picrylhydrazyl (DPPH) radical scavenging assay was performed according to Blois (1958) with minor modifications. Briefly, culture of the selected strains were adjusted to an $\mathrm{OD}_{600}$ of approximately 1.0 using PBS $(\mathrm{pH}$ 7.4) and were added to $0.05 \mathrm{mM}$ DPPH solution (1:2 $\mathrm{v} / \mathrm{v})$ and mixed well. Next, the mixtures were left to stand at room temperature for $30 \mathrm{~min}$ in the dark. The control reaction involved ethanol added to DPPH solution. The absorbance of each mixture was measured at $517 \mathrm{~nm}$. Each sample assay was performed in triplicate. The results were compared with those of ascorbic acid $(10 \mu \mathrm{g} / \mathrm{mL})$, and the antioxidant activity was calculated using the following formula: Scavenging effect $(\%)=(\mathrm{Ac}-\mathrm{As}) / \mathrm{Ac} \times 100$, where As is the absorbance of the test sample, and Ac is the absorbance of the control at $517 \mathrm{~nm}$.

The scavenging activity of the (2,2'-azino-bis(3-ethylbenzothiazoline-6-sulfonic acid)) (ABTS) radical was measured according to Re et al. (1999). Briefly, the radical cation was prepared by mixing $7 \mathrm{mM}$ of ABTS with $2.45 \mathrm{mM}$ potassium persulfate $(1: 1 \mathrm{v} / \mathrm{v})$ and leaving the mixture at room temperature in the dark for $24 \mathrm{~h}$. Next, $50 \mu \mathrm{L}$ of the selected strain sample and $100 \mu \mathrm{L}$ of ABTS solution were mixed and incubated for $10 \mathrm{~min}$ at room temperature. The absorbance of the mixture was measured at $734 \mathrm{~nm}$. Each sample assay was performed in triplicate, and the scavenging rate was calculated as follows: Scavenging rate $(\%)=($ Ac-As $) / A c \times 100$, where As is the absorbance of the test sample, and Ac is the absorbance of the control at $734 \mathrm{~nm}$.

\section{Cell culturing of RAW 264.7 cells}

The murine macrophage RAW 264.7 cell line was obtained from the Korean Cell Line Bank (KCLB, Korea) and incubated in DMEM (BD Biosciences) supplemented with 10\% fetal bovine serum (FBS; Gibco) and 1\% penicillin/streptomycin at $37{ }^{\circ} \mathrm{C}$ in $5 \% \mathrm{CO}_{2}$. The cells were sub-cultured and plated at $80-90 \%$ confluency.

\section{NO production}

RAW 264.7 macrophage cells were grown at $37{ }^{\circ} \mathrm{C}$ and 5\% $\mathrm{CO}_{2}$ in a fully humidified atmosphere and sub-cultured every 3 days to $95 \%$ confluency. For routine subcultures, DMEM was supplemented with $10 \%$ FBS, penicillin (100 units $/ \mathrm{mL}$ ), and streptomycin $(100 \mu \mathrm{g} / \mathrm{mL})$. NO formation was detected based on the accumulation of nitrite, an indicator of NO synthesis, in the culture medium via the Griess reaction 
(Lyons et al. 1992). RAW 264.7 cells were plated at $2 \times 10^{5}$ cells/well in a 96-well plate and stimulated with $1 \mu \mathrm{g} / \mathrm{mL}$ LPS, followed by the addition of isolated bacterial strains $\left(10^{9}\right.$ cells/well). After $24 \mathrm{~h}$ of incubation, NO concentration was determined by measuring the amount of nitrite in the cell culture supernatant using the Griess reagent. The absorbance at $550 \mathrm{~nm}$ wavelength was measured using the Epoch 2 microplate reader (BioTek, Winooski, VT, USA). Fresh culture medium was used as the blank control for all experiments.

3-[4,5-Dimethylthiazole-2-yl]-2,5-diphenyltetrazolium bromide (MTT; Sigma, USA) assay was performed to determine the viability of RAW 264.7 cells treated with the strains. RAW 264.7 cells were washed twice with PBS and $100 \mu \mathrm{L}$ of MTT reagent $(0.5 \mathrm{mg} / \mathrm{mL})$ dissolved with PBS was added to each well. After $1 \mathrm{~h}$ of incubation, the MTT reagent was discarded and $100 \mu \mathrm{L}$ of dimethyl sulfoxide (DMSO; Sigma, USA) was added to dissolve the formazan formed as a reactant between the MTT reagent and metabolites of live cells. The absorbance (A) was measured at $570 \mathrm{~nm}$ wavelength, and cytotoxicity was calculated in comparison with the result of a negative control group as follows.

Cell viability $(\%)=($ A sample $/$ A negative control $) \times 100$

\section{Semi-quantitative reverse transcription-polymerase chain reaction (RT-PCR)}

RT-PCR was performed to analyze the mRNA expression of inducible nitric oxide synthase (iNOS), cyclooxygenase 2 (COX-2), and TNF- $\alpha$. Total RNA was extracted from the RAW 264.7 cells using the TRI REGENT ${ }^{\text {TM }}$ (Sigma Aldrich, St. Louis, MO, USA) according to the manufacturer's instructions. iNOS, COX-2, and TNF- $\alpha$ primers were designed for RT-PCR. Glyceraldehydes-3-phosphate dehydrogenase (GAPDH) was used as a housekeeping gene to normalize all samples. Table 1 shows the sequences of the primer pairs used to amplify iNOS, COX-2, TNF- $\alpha$, and GAPDH. RT-PCR was performed using the ONE-STEP RT-PCR PreMix kit ${ }^{\mathrm{TM}}$ (Qiagen Inc., Valencia, CA, USA) according to the manufacturer's instructions. Each of the primers and $1 \mu \mathrm{g}$ of the RNA template were mixed with the ONE-STEP RT-PCR PreMix ${ }^{\mathrm{TM}}$. These samples were amplified via one step RT-PCR, under the following conditions: reverse transcription reaction at $95{ }^{\circ} \mathrm{C}$ for $5 \mathrm{~min} ; 30$ cycles of $95{ }^{\circ} \mathrm{C}$ for $45 \mathrm{~s}, 60^{\circ} \mathrm{C}$ for $45 \mathrm{~s}(\mathrm{COX}-2$ and GAPDH), and $72{ }^{\circ} \mathrm{C}$ for $1 \mathrm{~min}$ or 35 cycles of $95{ }^{\circ} \mathrm{C}$ for $45 \mathrm{~s}, 63{ }^{\circ} \mathrm{C}$ for $45 \mathrm{~s}$ (iNOS and TNF- $\alpha$ ), and $72{ }^{\circ} \mathrm{C}$ for $1 \mathrm{~min}$; and a final elongation step of $5 \mathrm{~min}$ at $72{ }^{\circ} \mathrm{C}$. The levels of iNOS, COX2 , and TNF- $\alpha$ mRNA expression were quantitated using a densitometer and using the Quantity One software (Bio-Rad, Hercules, CA, USA).

\section{Analysis of SCFAs present in the culture medium}

The SCFAs in the fermented broth were analyzed via gas chromatography-mass spectrometry (QP2020 NXW/ ORP230; Shimadzu, Japan) using the headspace solid-phase microextraction method (Thitiratsakul and Anprung 2014) with minor modifications. The samples were separated using a Stabilwax-DA column $(60 \mathrm{~m} \times 0.32 \mathrm{~mm} \times 0.25 \mu \mathrm{m}$, Shimadzu). Analytical conditions were as follows: oven temperature was held at $50{ }^{\circ} \mathrm{C}$ for $2 \mathrm{~min}$, and raised to $100{ }^{\circ} \mathrm{C}$ at $10^{\circ} \mathrm{C} / \mathrm{min}, 200{ }^{\circ} \mathrm{C}$ at $2{ }^{\circ} \mathrm{C} / \mathrm{min}$, increased to $220^{\circ} \mathrm{C}$ at $20^{\circ} \mathrm{C} /$ min, and maintained for $2 \mathrm{~min}$; the splitless mode was used; helium was used as the carrier gas at the flow of $2 \mathrm{~mL} / \mathrm{min}$. The mass spectrometer was operated in the electron-impact mode at $65 \mathrm{eV}$. The scan range was $40-200 \mathrm{~m} / \mathrm{z}$, the scan rate was $0.2 \mathrm{~s} / \mathrm{scan}$, and the electron energy was $70 \mathrm{eV}$. The ionization source and quad temperature were at $200{ }^{\circ} \mathrm{C}$ and $150^{\circ} \mathrm{C}$, respectively. Each extracted sample peak area was normalized to the initial volume of the sample following quantification. Linear regression equations for each analyte
Table 1 Primer sequences of the primers used for reverse transcription-polymerase chain reaction assay

\begin{tabular}{lll}
\hline Gene & & Sequence \\
\hline TNF- $\alpha$ & Sense & 5'-AGCCCACGTCGTAGCAAACCACCAA-3' \\
& Antisense & 5'-AACACCCATTCCCTTCACAGAGCA \\
& & AT-3' \\
iNOS & Sense & 5'-CCCTTCCGAAGTTTCTGGCAGC-3' \\
& Antisense & 5'-GGCTGTCAGAGCCTCGTGGCTT-3' $^{\prime}$ \\
COX-2 & Sense & 5'-GGAGAGACTATCAAGATAGTGATC-3' $^{\prime}$ \\
AAPDH & Antisense & 5'-ATGGTCAGTAGACTTTTACAGCTC-3' $^{\prime}$ \\
& Sense & 5'-TGAAGGTCGGTGTGAACGGATTTG $^{\prime}$ \\
& Antisense & GC-3' \\
\hline
\end{tabular}

$T N F-\alpha$ tumor necrosis factor alpha; iNOS inducible nitric oxide synthase; $C O X-2$ cyclooxygenase 2; $G A P D H$ glyceraldehyde-3-phosphate dehydrogenase 
were calculated with the calibration curve of the peak area versus analyte concentrations $(\mu \mathrm{mol})$.

\section{Statistical analysis}

Results are expressed as the mean \pm standard deviation of three experiments. The difference between groups was evaluated using the Student's $t$ test, and a $P$ value of $<0.05$ was considered significant.

\section{Results and discussion}

\section{In vitro antioxidation properties of samples}

The antioxidant activities of the 18 samples (17 strains and mixture sample) were evaluated by measuring the DPPH and ABTS radical scavenging activities. The DPPH free radical scavenging activity of the postbiotic samples ranged from 17.8 to $90.6 \%$ (Table. 2). Bifidobacterium bifidum MG731 showed the highest radical scavenging activity (90.6\%) followed by Bi. lactis MG741 (59.6\%). The ABTS radical scavenging activity of the samples ranged from 27.1 to 99.5\% (Table. 1). Bi. lactis MG741 showed the highest radical scavenging activity (99.5\%) followed by Lactobacillus plantarum MG989 (98.9\%), L. salivarius MG242 (97.1\%), and Bi. bifidum MG731 (96.1\%). In this context, de Oliveira Coelho et al. (2019) reported that both the intracellular and extracellular contents of Lactobacillus satsumensis,
Leuconostoc mesenteroides, and Saccharomyces cerevisiae showed antioxidant activity ranging from 20 to $28 \%$ of the DPPH inhibition. L. satsumensis and S. cerevisiae showed the highest intracellular and extracellular activities (approximately $28 \%$ of DPPH inhibition), respectively. Similarly, Amaretti et al. (2013) reported antioxidant activities of intracellular postbiotics from 7 Bifidobacterium, 11 Lactobacillus, 6 Lactococcus, and 10 Streptococcus thermophilus strains. Afify et al. (2012) reported that $L$. reuteri showed ABTS radical scavenging effects. Lin and Yen (1999) evaluated the inhibitory effect of Bifidobacterium longum, and Kim et al. (2003) isolated Bifidobacterium species showing antioxidant activity from infant fecal samples.

\section{Cytotoxicity and NO production}

NO is a multi-functional mediator and plays a pivotal role in the immune response to inflammatory activity. The physiological or normal NO production in phagocytes is beneficial for the host defense against microorganisms, parasites, and tumor cells (Lin and Lin 1997; Korhonen et al. 2001). Results of the NO assay showed that the postbiotic samples showed a wide range of NO production levels (Fig. 1). This result indicated that the postbiotic samples might had different functional properties, even if they belong to the same species. Among the samples, Bi. bifidum MG731 exhibited the lowest NO production $(4.28 \mu \mathrm{M})$ in LPS-stimulated cells, followed by Bi. lactis MG741 (10.80 $\mu \mathrm{M})$, L. salivarius MG242 (14.60 $\mu \mathrm{M})$, and L. plantarum MG989 (19.60 $\mu \mathrm{M})$.
Table 2 Radical scavenging activity of heat-killed culture samples

\begin{tabular}{|c|c|c|c|}
\hline Isolated from & Samples & $\begin{array}{l}\text { DPPH radical scaveng- } \\
\text { ing }(\%)\end{array}$ & $\begin{array}{l}\text { ABTS radical } \\
\text { scavenging }(\%)\end{array}$ \\
\hline Breast milk & L. reuteri MG505 & $40.9 \pm 9.2$ & $60.9 \pm 2.8$ \\
\hline \multirow[t]{4}{*}{ Infant feces } & Bi. longum MG723 & $51.9 \pm 3.7$ & $75.2 \pm 0.5$ \\
\hline & Bi. breve MG729 & $50.2 \pm 1.7$ & $76.6 \pm 0.1$ \\
\hline & Bi. bifidum MG731 & $90.6 \pm 2.3$ & $96.1 \pm 0.4$ \\
\hline & Bi. lactis MG741 & $59.6 \pm 2.1$ & $99.5 \pm 0.7$ \\
\hline Human & L. gasseri $\mathrm{MG} 4247$ & $31.7 \pm 2.9$ & $62.2 \pm 0.3$ \\
\hline \multirow[t]{3}{*}{ Human vagina } & L. salivarius MG242 & $56.9 \pm 6.0$ & $97.1 \pm 0.4$ \\
\hline & L. fermentum MG901 & $22.4 \pm 5.6$ & $48.0 \pm 1.8$ \\
\hline & L. plantarum MG989 & $59.4 \pm 3.8$ & $98.9 \pm 0.5$ \\
\hline \multirow[t]{8}{*}{ Fermented food } & L. paracasei MG310 & $19.5 \pm 5.0$ & $28.2 \pm 0.9$ \\
\hline & L. casei MG311 & $19.4 \pm 11.5$ & $29.3 \pm 0.7$ \\
\hline & L. rhamnosus MG316 & $42.5 \pm 10.5$ & $49.2 \pm 0.6$ \\
\hline & L. bulgaricus MG515 & $51.7 \pm 2.8$ & $76.1 \pm 8.3$ \\
\hline & L. helveticus MG585 & $45.3 \pm 4.2$ & $84.0 \pm 0.6$ \\
\hline & Lac. lactis MG5125 & $18.4 \pm 1.8$ & $47.8 \pm 1.6$ \\
\hline & S. thermophilus MG5140 & $17.8 \pm 1.6$ & $27.1 \pm 0.4$ \\
\hline & L. acidophilus MG5228 & $55.9 \pm 4.0$ & $87.4 \pm 1.4$ \\
\hline Mixture & & $44.1 \pm 0.8$ & $73.6 \pm 0.3$ \\
\hline
\end{tabular}

DPPH, 2,2-diphenyl-1-picrylhydrazyl; ABTS, 2,2'-azino-bis(3-ethylbenzothiazoline-6-sulfonic acid) 


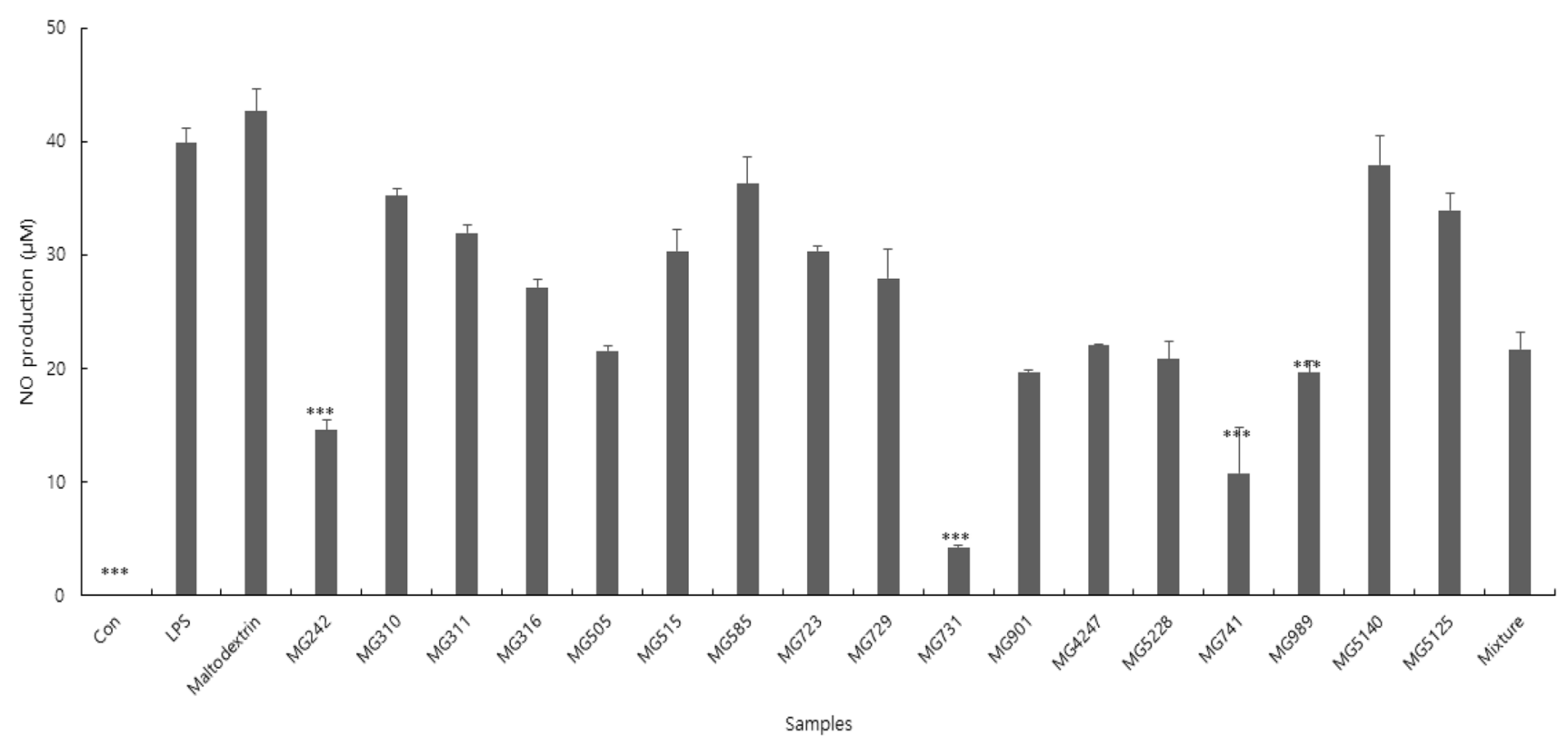

Fig. 1 Inhibition of nitric oxide production in LPS-stimulated RAW264.7 cells treated with 18 samples (17 strains and mixture sample). The results are presented as mean \pm standard deviation of three independent experiments $(n=3)$. *** $P<.001$, versus LPS

To examine cytotoxicity, MTT assays were performed using the RAW 264.7 cells (data not shown). When treated with 18 samples, the cell viability ranged from 72.20 to $98.29 \%$. Thus, the lowest NO production strains upregulated that cytokine expression and activated upstream pathways related to RAW 264.7 cells activation. Moreover, these strains were could be helpful in against invading pathogens via macrophage activation.

\section{Selected strains suppressed iNOS, COX-2, and TNF-a expression in LPS-stimulated RAW 264.7 cells}

NO and prostaglandins are modulated by distinct NOS and COX isoforms, respectively, and are important biomarkers in the inflammatory responses that induce pain, swelling, fever, and tenderness (Hu et al. 2008). Among the isoforms of these enzymes, iNOS and COX-2 are undetectable at the basal state. Using RT-PCR, we investigated whether selected strains (L. salivarius MG242, L. plantarum MG989, Bi. bifidum MG731, and Bi. lactis MG741) could regulate the expression of iNOS, COX-2, and TNF- $\alpha$. As expected, treatment with LPS markedly increased the mRNA levels of iNOS, COX-2, and TNF- $\alpha$, which were downregulated following treatment with the selected strains (Fig. 2a-c). The expression of the housekeeping gene GAPDH was not affected by the selected strains. These results indicated that treatment using selected strains might have inhibited the production of NO via the downregulation of iNOS and COX-2. Similarly, previous studies showed that treatment using heatkilled Lactobacillus brevis K65 decreases the production of
NO in the RAW 264.7 cells upon LPS stimulation, which may be attributed to downregulated iNOS and COX-2 (Liu et al. 2016).

\section{Analysis of the SCFAs present in culture medium}

Probiotics can produce various metabolites that antioxidant activity such as glutathione, butyrate, and folate. SCFAs, that are the major products of microbial fermentation of carbohydrates, can suppress the growth of pathogenic intestinal bacteria, and modulate lipid metabolism and the immune system (Rodrigues et al. 2016). In addition, SCFAs lower the intestinal $\mathrm{pH}$ and promote the bioavailability of minerals such as magnesium and calcium, thereby inhibiting the growth of harmful bacteria (Gullon et al. 2014).

The SCFA profile of the samples including the compounds and their concentrations is shown in Table 3. Acetic acid is the main SCFA produced by many intestinal bacteria in the human gut (Gullon et al. 2015), and was the most abundant SCFA found in this study. In addition, acetic acid is the metabolite generated the most during Bifidobacterium fermentation (Khodaei et al. 2016). The Bifidobacterium species showed a higher acetic acid production (356.0-4995.0 $\mu \mathrm{g} / \mathrm{g})$ than that of other species $(316.0-1489.0 \mu \mathrm{g} / \mathrm{g})$. These results suggest that the differences in the fermentation ability of specific strains may be due to the carbon chain length of the polysaccharides (Shalini et al. 2017). Lactobacillus acidophilus MG5228 showed a significantly higher propionic acid $(19.9 \mu \mathrm{g} / \mathrm{g})$ and butyric acid $(80.7 \mu \mathrm{g} / \mathrm{g})$ production than those of other strains. Propionic acid has been reported to reduce the activity

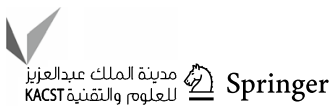



mRNA expression of (a) TNF$\alpha,(\mathbf{b})$ iNOS, and (C) COX-2. Values shown are mean \pm standard deviation of three independent experiments. $* P<.05$; $* * P<.01 ; * * * P<.001$, versus LPS
Fig. 2 RT-PCR analysis of the
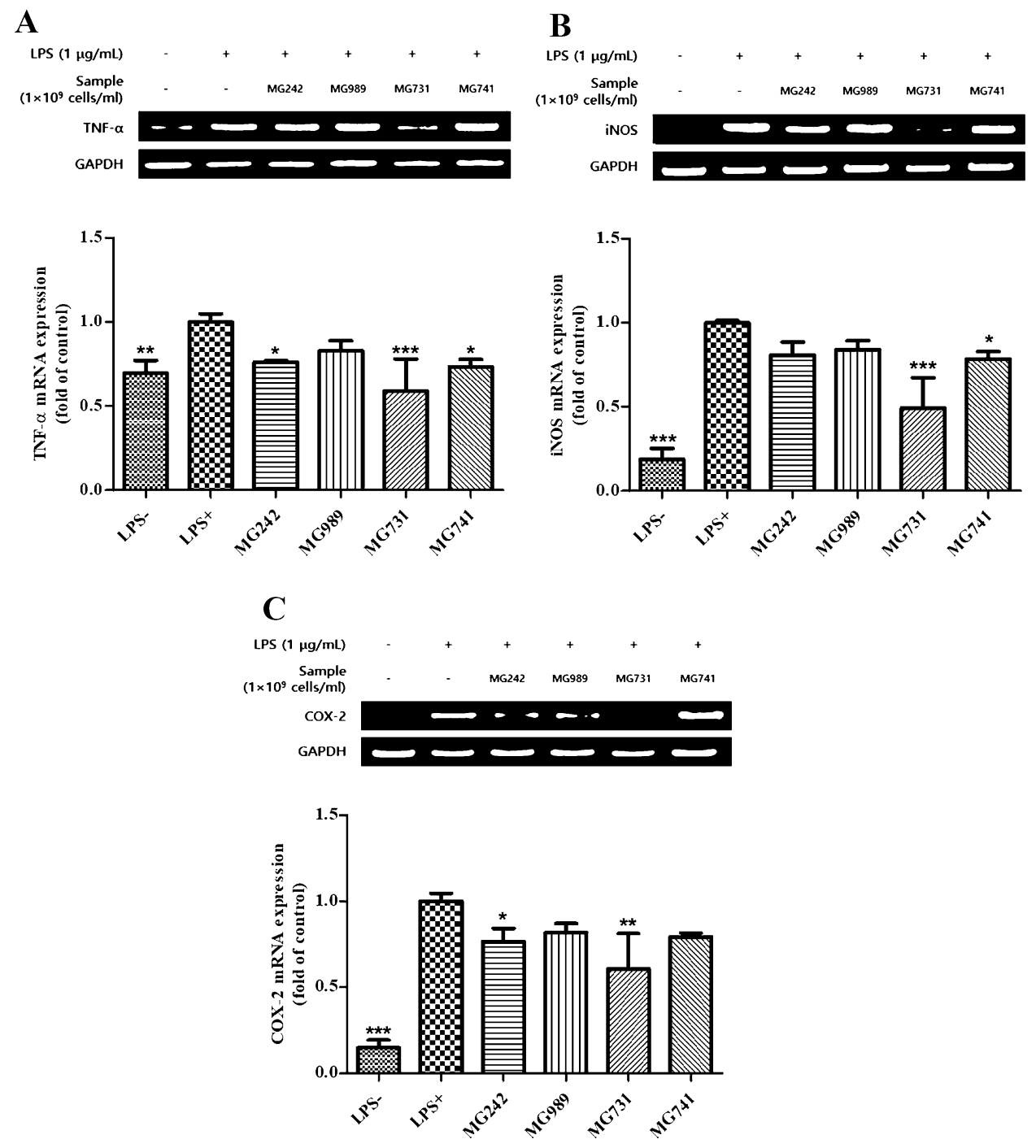

of Escherichia coli and Salmonella spp. and has an anti-cholesterolemic effect (Khodaei et al. 2016). Butyrate is a SCFA produced by microbiota in the colon and distal small intestine from residual starch, dietary fiber, and low-digestible polysaccharides via fermentation (Kau et al. 2011). The MIYAIRI 588 strain of Clostridium butyricum is a butyrate-producing probiotic. It has recently been shown to induce antioxidases in rats with nonalcoholic fatty liver disease to suppress hepatic oxidative stress (Endo et al. 2013). The levels of antioxidant metabolites in the host can also be regulated via probiotic treatment. Furthermore, probiotics and their metabolites such as SCFAs play an essential role in human immune function (Sawicki et al. 2017).

\section{Conclusion}

The aim of this study was conducted with identifying superior postbiotic samples that showed desired antioxidant activity and production of SCFAs among 17 strains isolated from Korean individuals and fermented foods. We selected four strains that showed high antioxidant activity. Food products that comprise live probiotics as food ingredients require low temperature and anaerobic conditions to prolong shelf-life, which increases the cost of packaging and distribution. The use of heat-killed cells that still maintain their bioactivity can prolong the shelf-life and 
Table 3 Short-chain fatty acid profile of 18 samples

\begin{tabular}{|c|c|c|c|c|}
\hline Samples & $\mathrm{AA}(\mu \mathrm{g} / \mathrm{g})$ & $\mathrm{PA}(\mu \mathrm{g} / \mathrm{g})$ & $\mathrm{BA}(\mu \mathrm{g} / \mathrm{g})$ & Total SCFA $(\mu \mathrm{g} / \mathrm{g})$ \\
\hline L. salivarius MG242 & $1455.0 \pm 6.8$ & $0.95 \pm 1.36$ & $0.15 \pm 0.05$ & $1456.1 \pm 8.2$ \\
\hline L. paracasei MG310 & $867.0 \pm 4.3$ & $0.45 \pm 0.06$ & $0.05 \pm 0.02$ & $867.5 \pm 4.4$ \\
\hline L. casei MG311 & $802.0 \pm 4.9$ & $1.55 \pm 0.27$ & $2.05 \pm 0.17$ & $805.6 \pm 5.3$ \\
\hline L. rhamnosus MG316 & $1354.0 \pm 9.4$ & $1.15 \pm 0.12$ & $0.20 \pm 0.08$ & $1355.4 \pm 9.6$ \\
\hline L. reuteri MG505 & $1444.0 \pm 9.2$ & $0.85 \pm 0.05$ & $0.05 \pm 0.02$ & $1444.9 \pm 9.3$ \\
\hline L. bulgaricus MG515 & $316.0 \pm 3.2$ & $0.50 \pm 0.01$ & $0.65 \pm 0.03$ & $317.2 \pm 3.2$ \\
\hline L. helveticus MG585 & $1153.0 \pm 9.3$ & $0.95 \pm 0.15$ & $0.20 \pm 0.01$ & $1154.2 \pm 9.5$ \\
\hline Bi. longum MG723 & $3902.0 \pm 14.9$ & $0.60 \pm 0.23$ & $0.65 \pm 0.03$ & $3903.3 \pm 15.2$ \\
\hline Bi. breve MG729 & $356.0 \pm 1.2$ & $0.30 \pm 0.07$ & $0.45 \pm 0.01$ & $356.8 \pm 1.3$ \\
\hline Bi. bifidum MG731 & $4995.0 \pm 22.6$ & $1.55 \pm 0.26$ & $2.00 \pm 0.35$ & $4998.6 \pm 23.2$ \\
\hline Bi. lactis MG741 & $2610.0 \pm 19.2$ & $1.83 \pm 0.03$ & $2.05 \pm 0.21$ & $2613.9 \pm 19.4$ \\
\hline L. fermentum MG901 & $1294.0 \pm 8.7$ & $0.50 \pm 0.02$ & $0.00 \pm 0.00$ & $1294.5 \pm 8.7$ \\
\hline L. plantarum MG989 & $628.4 \pm 2.7$ & $0.88 \pm 0.07$ & $0.93 \pm 0.18$ & $630.2 \pm 3.0$ \\
\hline L. gasseri MG4247 & $428.0 \pm 1.8$ & $0.30 \pm 0.02$ & $0.25 \pm 0.02$ & $428.6 \pm 1.8$ \\
\hline Lac. lactis MG5125 & $1253.4 \pm 4.3$ & $1.03 \pm 0.09$ & $0.48 \pm 0.08$ & $1254.9 \pm 4.5$ \\
\hline S. thermophilus MG5140 & $971.7 \pm 2.9$ & $0.93 \pm 0.04$ & $0.23 \pm 0.03$ & $972.9 \pm 3.0$ \\
\hline L. acidophilus MG5228 & $1489.0 \pm 2.6$ & $19.90 \pm 0.40$ & $80.70 \pm 3.63$ & $1589.6 \pm 6.6$ \\
\hline Mixture & $871.7 \pm 2.7$ & $3.60 \pm 0.56$ & $4.68 \pm 0.34$ & $880.0 \pm 3.6$ \\
\hline
\end{tabular}

$A A$ acetic acid; $P A$ propionic acid; $B A$ butyric acid

Data are presented as mean \pm standard deviation $(n=3)$ simplify the food processing steps of probiotic-containing foods owing to their high stability. The antioxidant and immune-modulating activities of selected strains in heatkilled forms show a strong potential for their usage in the manufacture of probiotic products.

Author contributions Conceptualization, C-HK; methodology, J-SK and HMP and SYK; validation, C-HK; formal analysis, C-HK; investigation, $\mathrm{C}-\mathrm{HK}$; resources, $\mathrm{N}$-SP; data curation, $\mathrm{C}-\mathrm{HK}$; writing - original draft preparation, C-HK; writing—review and editing, N-SP.

Funding This research received no external funding.

Data availability The authors declare that all data and materials support published claims and comply with feld standards.

\section{Declarations}

Conflict of interest The authors declare no conflicts of interest.

Open Access This article is licensed under a Creative Commons Attribution 4.0 International License, which permits use, sharing, adaptation, distribution and reproduction in any medium or format, as long as you give appropriate credit to the original author(s) and the source, provide a link to the Creative Commons licence, and indicate if changes were made. The images or other third party material in this article are included in the article's Creative Commons licence, unless indicated otherwise in a credit line to the material. If material is not included in the article's Creative Commons licence and your intended use is not permitted by statutory regulation or exceeds the permitted use, you will need to obtain permission directly from the copyright holder. To view a copy of this licence, visit http://creativecommons.org/licenses/by/4.0/.

\section{References}

Afify AEMMR, Romeilah RM, Sultan SI, Hussein MM (2012) Antioxidant activity and biological evaluations of probiotic bacteria strains. Int J Acad Res 4:131-139

Aguilar-Toalá JE, Garcia-Varela R, Garcia HS, Mata-Haro V, GonzálezCórdova AF, Vallejo-Cordoba B, Hernández-Mendoza A (2018) Postbiotics: an evolving term within the functional foods field. Trends Food Sci Technol 75:105-114

Amaretti A, di Nunzio M, Pompei A, Raimondi S, Rossi M, Bordoni A (2013) Antioxidant properties of potentially probiotic bacteria: in vitro and in vivo activities. Appl Microbiol Biotechnol 97(2):809-817

Blois MS (1958) Antioxidant determinations by the use of a stable free radical. Nature 181:1199-1200

de Almada CN, Almada CN, Martinez RCR, Sant'Ana AS (2016) Paraprobiotics: evidences on their ability to modify biological responses, inactivation methods and perspectives on their application in foods. Trends Food Sci Technol 58:96-114

de Oliveira CB, Fiorda-Mello F, de Melo Pereira GV, Thomaz-Soccol V, Rakshit SK, de Carvalho JC, Soccol CR (2019) In vitro probiotic properties and DNA protection activity of yeast and lactic acid bacteria isolated from a honey-based kefir beverage. Foods 8(10): 485

Endo H, Niioka M, Kobayashi N, Tanaka M, Watanabe T (2013) Butyrate-producing probiotics reduce nonalcoholic fatty liver disease progression in rats: new insight into the probiotics for the gut-liver axis. PLoS ONE 8(5):e63388

Gullón B, Gullón P, Tavaria F, Pintado M, Gomes AM, Alonso JL, Parajó JC (2014) Structural features and assessment of prebiotic activity of refined arabinoxylooligosaccharides from wheat bran. J Funct Foods 6:438-449

Gullón B, Pereira M, Mestres C, Hounhouigan J, Pallet D, Alonso JL, Pintado M (2015) Assessment of prebiotic potential of

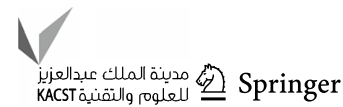


Akpan-yoghurt-like product and effects on the human intestinal microbiota. J Funct Foods 19:545-553

Hu SS, Bradshaw HB, Chen JS, Tan B, Walker JM (2008) Prostaglandin E2 glycerol ester, an endogenous COX-2 metabolite of 2-arachidonoylglycerol, induces hyperalgesia and modulates NFkB activity. Br J Pharmacol 153:1538-1549

Kau AL, Ahern PP, Griffin NW, Goodman AL, Gordon JI (2011) Human nutrition, the gut microbiome and the immune system. Nature 474(7351):327-336

Kazemi A, Noorbala AA, Azam K, Djafarian K (2019) Effect of prebiotic and probiotic supplementation on circulating proinflammatory cytokines and urinary cortisol levels in patients with major depressive disorder: a double-blind, placebo controlled randomized clinical trial. J Funct Foods 52:596-602

Khodaei N, Fernandez B, Fliss I, Karboune S (2016) Digestibility and prebiotic properties of potato rhamnogalacturonan I polysaccharide and its galactose-rich oligosaccharides/oligomers. Carbohydr Polym 136:1074-1084

Kim JY, Choi SI, Heo TR (2003) Screening of antioxidative activity of Bifidobacterium species isolated from Korean infant feces and their identification. Biotechnol Bioprocess Eng 8:199-204

Kim HM, Kim JS, Kim YG, Jeong YL, Kim JE, Paek NS, Kang CH (2020) Antioxidant and probiotic properties of Lactobacilli and Bifidobacteria of human origins. Biotechnol Bioprocess Eng 25:421-430

Klein G, Pack A, Bonaparte C, Reuter G (1998) Taxonomy and physiology of probiotic lactic acid bacteria. Int J Food Microbiol 41:103-125

Koh A, De Vadder F, Kovatcheva-Datchary P, Backhed F (2016) From dietary fiber to host physiology: short-chain fatty acids as key bacterial metabolites. Cell 165(6):1332-1345

Korhonen R, Korpela R, Saxelin M, Mäki M, Kankaanranta H, Moilanen E (2001) Induction of nitric oxide synthesis by probiotic Lactobacillus rhamnosus GG in J774 macrophages and human T84 intestinal epithelial cells. Inflammation 25:223-232

Lin MY, Yen CL (1999) Inhibition of lipid peroxidation by Lactobacillus acidophilus and Bifidobacterium longum. J Agric Food Chem 47:3661-3664

Liu YW, Ong WK, Su YW, Hsu CC, Cheng TH, Tsai YC (2016) Antiinflammatory effects of Lactobacillus brevis K65 on RAW 264.7 cells and in mice with dextran sulphate sodium induced ulcerative colitis. Benef Microbes 7(3):387-396
Lyons CR, Orloff GJ, Cunningham JM (1992) Molecular cloning and functional expression of an inducible nitric oxide synthase from a murine macrophage cell line. J Biol Chem 267(9):6370-6374

Re R, Pellegrini N, Proteggente A, Pannala A, Yang M, Rice-Evans C (1999) Antioxidant activity applying an improved ABTS radical cation decolorization assay. Free Radic Biol Med 26:1231-1237

Redondo N, Gheorghe A, Díaz LE, Villavisencio B, Marcos A, Nova E (2019) Associations of probiotic fermented milk (PFM) and yogurt consumption with Bifidobacterium and Lactobacillus components of the gut microbiota in healthy adults. Nutr 11(3):651

Rodrigues D, Walton G, Sousa S, Rocha-Santos TAP, Duarte AC, Freitas AC, Gomes AMP (2016) In vitro fermentation and prebiotic potential of selected extracts from seaweeds and mushrooms. Lwt Food Sci Technol 73:131-139

Sawicki CM, Livingston KA, Obin M, Roberts SB, Chung M, McKeown NM (2017) Dietary fiber and the human gut microbiota: application of evidence mapping methodology. Nutrients 9(2):125

Shalini R, Abinaya G, Saranya P, Antony U (2017) Growth of selected probiotic bacterial strains with fructans from Nendran banana and garlic. Lwt Food Sci Technol 83:68-78

Sharma M, Shukla G (2016) Metabiotics: one step ahead of probiotics; an insight into mechanisms involved in anticancerous effect in colorectal cancer. Front Microbiol 7:1940-1940

Singh N, Gurav A, Sivaprakasam S et al (2014) Activation of Gpr109a, receptor for niacin and the commensal metabolite butyrate, suppresses colonic inflammation and carcinogenesis. Immunity 40(1):128-139

Smith PM, Howitt MR, Panikov N, Michaud M, Gallini CA, BohloolyYM GJN, Garrett WS (2013) The microbial metabolites, shortchain fatty acids, regulate colonic Treg cell homeostasis. Science 341(6145):569-573

Thitiratsakul B, Anprung P (2014) Prebiotic activity score and bioactive compounds in longan (Dimocarpus longan Lour): influence of pectinase in enzyme-assisted extraction. J Food Sci Technol 51(9):1947-1955

Willemsen LEM, Koetsier MA, van Deventer SJH, van Tol EAF (2003) Short chain fatty acids stimulate epithelial mucin 2 expression through differential effects on prostaglandin $\mathrm{E}(1)$ and $\mathrm{E}(2)$ production by intestinal myofibroblasts. Gut 52(10):1442-1447 